\title{
Rice husk as an alternative energy for cement production and its effect on the chemical properties of cement
}

\author{
Agus Maryoto, ${ }^{1, *}$ and Gathot Heri Sudibyo ${ }^{1}$ \\ ${ }^{1}$ Department of Civil Engineering, Engineering Faculty, Jenderal Soedirman University, Indonesia
}

\begin{abstract}
Production of rice husk in Central Java province is around $2,825,000$ tonnes annually. It can be used as an alternative energy source to substitute coal in combustion during cement production. This study was conducted to determine the impact of rice husk as a substitute energy source in cement production. The observations of rice husk comprised calorimetric tests, physical and chemical tests, and percentage rice husk substitution for coal as firing energy. The chemical properties of the cement tested include the chemical content, $\mathrm{MgO}$ and $\mathrm{SO}_{3}$ contents, loss on ignition, insoluble residue, and total alkali. The results show that the chemical content of cement which is produced using rice husk as a substitute for coal in the combustion process still meets the Indonesian National Standard.
\end{abstract}

\section{Background}

Cement is a building material made of limestone, clay, iron sand, and silica sand in a certain ratio. The materials are milled together until smooth and then burned in a rotary kiln. The combustion temperature in the rotary kiln reaches a temperature of $1350{ }^{\circ} \mathrm{C}$. The products of combustion are then cooled suddenly. The product is commonly referred to as clinker. Coal is the main fuel used for burning in rotary kilns. Unfortunately, coal is a non-renewable fuel. On the other hand, Indonesia is a large producer of rice annually. Rice husk is a biomass waste from the rice production process. The amount of rice husks produced in Central Java has reached 2,825 million tonnes annually.

Some researchers have conducted laboratory-scale research to determine the effect of using husk ash as a cement substitute. The results showed that substitution of rice husk ash for cement could increase the compressive strength of concrete [1,2]. Rice husk ash can be combined with fly ash as a substitute for cement in concrete [3]. Its use could replace $20 \%$ to $30 \%$ of the cement $[4,5]$. The concrete compressive strength can be increased by the use of rice husk ash which is burned at a temperature of $500{ }^{\circ} \mathrm{C}[6]$.

The combination of application of rice husk ash and silica fume in concrete $[7,8]$ produces concrete with high compressive strength. In addition, concrete with rice husk ash content burned at $800{ }^{\circ} \mathrm{C}$ also shows increased temperature resistance. Other properties of concrete

*Corresponding author: agus_maryoto1971@yahoo.co.id 
are improved due to the use of fly ash, namely the tensile strength, water absorption [9], and durability $[10,11]$.

The use of rice husk as a substitute for coal fuel in the cement industry has sophisticated potential. This is because it has an excellent effect on improving the concrete properties. The physical properties of rice husk in the form of small grains also offers advantages when used as a substitute for coal fuel in the cement industry. This study aims to determine the effect of the use of rice husk in the cement industry on the chemical properties of cement. Prior to being used as a substitute for coal fuel, the physical properties and calorific value content of rice husks are identified, thereby reducing the amount of coal used for combustion in undisturbed clinker production.

\section{Method}

\subsection{Testing of rice husk}

The materials used in this study are cement type I, crushed stone, sand, and water. The mixed proportions of concrete are obtained after testing the physical properties of crushed stone and sand. Tests on the physical properties of crushed stone and sand consist of density, specific gravity, mud content, and sieve analyses. The test data are used to create the mix design as listed in Table 1. This research uses equipment such as a concrete mixer, a cylinder mould with a diameter of $150 \mathrm{~mm}$ and height of $300 \mathrm{~mm}$, a tamping rod, slump apparatus, a base plate, an internal electrical vibrator, a rubber hammer, a leveller, and a thermometer.

Table 1. Types and amount of tests on rice husk.

\begin{tabular}{|c|l|c|}
\hline No & \multicolumn{1}{|c|}{ Type of Tests } & Number of Tests \\
\hline 1 & Percentage of rice husk & 12 \\
\hline 2 & Calorific content & 12 \\
\hline 3 & Density & 12 \\
\hline 4 & Water content & 12 \\
\hline 5 & Chemical content of rice husk ash & 1 \\
\hline
\end{tabular}

The amount of rice husk used for burning in the rotary kiln can be monitored through the weight feeder burner. The weight feeder automatically records how much rice husk has been used. The recording is done three times per day at 08.00, 11.00, and 14.00 hours.

The process of calorific analysis of rice husk is done using a bomb calorimeter. A certain amount of the substance to be tested is placed on a platinum plate and a known "heavy iron coil" (which will also be burned) is also placed on the platinum plate so as to adhere to the substance which will be tested. The bomb calorimeter is then closed and the lid is tightened, after which the "bomb" is filled with $\mathrm{O}_{2}$ until the pressure reaches $25 \mathrm{Atm}$. Then the "bomb" is inserted into a water-filled calorimeter. After everything has been arranged, a certain amount of electricity is supplied to the iron wire and after burning, the temperature rise is measured. The calculation of the calorific value of the sample can be calculated using the following formula.

$$
H c=\frac{W \cdot T-e_{1}-e_{2}-e_{3}}{m}
$$


where $\mathrm{H}_{\mathrm{c}}$ is the gross heat of combustion, $\mathrm{T}$ is the temperature rise, $\mathrm{W}$ is the energy equivalent used, $\mathrm{e}_{1}$ is the correction of $\mathrm{HNO}_{3}, \mathrm{e}_{2}$ is the heat correction of $\mathrm{H}_{2} \mathrm{SO}_{4}, \mathrm{e}_{3}$ is the heat correction of the wire, and $\mathrm{m}$ is the weight of the sample.

The density of rice husk can be found by placing the rice husk into a container with a certain volume (V) and compacting it tightly. Containers with rice husk are weighed (B). The net weight of rice husk is obtained by subtracting the weight of the container (A) from the weight of $\mathrm{B}$. The weight of the rice husk content can be calculated by the following equation.

$$
\operatorname{Density}\left(\mathrm{kg} / \mathrm{m}^{3}\right)=\frac{B-A}{V}
$$

The water content of rice husk can be analysed by weighing the rice husk $\left(\mathrm{W}_{1}\right)$. The rice husk is then dried in the oven until its moisture content is completely lost. The rice husk is weighed in dry conditions $\left(\mathrm{W}_{2}\right)$. The water content of rice husk can be calculated by the following equation:

$$
\text { Water content }(\%)=\frac{W_{1}-W_{2}}{W_{1}} \times 100 \%
$$

The chemical content of rice husk ash was analysed by X-ray Diffraction (XRD). XRD is used for analysis of the composition of phases or compounds in the material as well as the characterization of crystals. The basic principle of XRD is to diffract light through the crystal gap. The diffraction of light by these lattices or crystals can occur when the diffraction comes from a radius having a wavelength equal to the distance between atoms, which is about $1 \AA$. The radiation used in the form of X-ray radiation electrons and X-ray neutrons is a photon with high energy that has a wavelength ranging from 0.5 to $2.5 \AA$. When the X-ray beam interacts with a material, some of the rays will be absorbed, transmitted, and partly scattered diffracted. This diffraction scatter is detected by XRD. Rays are dissipated. There are mutually eliminating because the phase of rays is different and there are also mutually strengthen because the phase of rays is same. Integrating rays from X-ray amplified are called diffraction of ray.

\subsection{Chemical content of cement}

Testing of $\mathrm{MgO}$, loss on ignition, insoluble residue, $\mathrm{SO}_{3}$, and alkaline content was conducted according to SNI 15-2049-2015 [12] on Portland cement. The MgO content testing procedure is as follows. The filtrate from the $\mathrm{CaO}$ determined previously was acidified with a $\mathrm{HCl}$ solution. The solution was evaporated by boiling until it reached a volume of $250 \mathrm{ml}$. The solution was cooled to room temperature. Then, $10 \mathrm{ml}$ of ammonium phosphate and $30 \mathrm{ml}$ of ammonium hydroxide were added to the solution. The solution was stirred for 10 to 15 minutes. The solution was left at room temperature for a minimum of 8 hours. The residue was washed five to six times with ammonium hydroxide. The residue was placed in a porcelain dish and immersed in a crucible until the filter paper had burned and then left at $1100{ }^{\circ} \mathrm{C}$ for 30 to 45 minutes. The residue of magnesium pyrophosphate was weighed. The $\mathrm{MgO}$ content was calculated using the following formula:

$$
\mathrm{MgO}(\%)=\mathrm{W} \times 72.4
$$

where $\mathrm{W}$ is the weight of magnesium pyrophosphate (gram) and 72.4 is the 2 molecular of $\mathrm{MgO}$ to magnesium pyrophosphate ratio divided by the sample weight used $(0.5 \mathrm{~g})$ multiplied by 100 .

The loss on ignition testing procedure is as follows. Cement is heated in the furnace at a pre-set temperature. The missing part is assumed to determine the amount of water and $\mathrm{CO}_{2}$ in the cement. One gram of cement was placed on a platinum plate whose weight was already 
known. The platinum plate and cement were heated in a furnace at a temperature of $950 \pm 50$ ${ }^{\circ} \mathrm{C}$ to a constant weight. Initial heating was done for a minimum of 15 minutes and subsequent heating for a minimum of 5 minutes. Loss on ignition can be calculated using the following equation:

$$
\text { Loss on ignition }(\%)=\frac{\text { Initial weight }- \text { Final weight after burning }}{\text { Initial weight }} \times 100 \%
$$

The insoluble residue testing procedure is as follows. One gram of cement was put into a $250 \mathrm{ml}$ glass and $25 \mathrm{ml}$ of water and $5 \mathrm{ml}$ of $\mathrm{HCl}$ were added. The solution was heated and stirred until complete decomposition took place. The solution was diluted with hot water until a volume of $50 \mathrm{ml}$ was reached and heated to near its boiling point. The solution was filtered with filter paper 41 and poured into a $600 \mathrm{ml}$ glass. The precipitate was washed at least 14 times with hot water so that it was free of chloride. The filter paper and the precipitated product were transferred to the glass, and $100 \mathrm{ml}$ of hot $100 \% \mathrm{NaOH}$ solution water was added. The solution was heated for 15 minutes at a temperature around the boiling point while occasionally stirring. The solution was acidified with $\mathrm{HCl}$ until it reached a methyl red colour. Then, 4 to 5 drops of $\mathrm{HCl}$ were added. The solution was filtered with filter paper 41 and the precipitated product was washed with hot $\mathrm{NH}_{4} \mathrm{NO}_{3}$ solution until the red indicator faded. The filter paper and its contents were placed on a platinum plate and discharged at $900-1000{ }^{\circ} \mathrm{C}$ for 30 minutes. The desiccator was cooled and weighed. The insoluble residue could be calculated by the following equation:

$$
\text { Insoluble Residue }=\frac{\text { Precipitated product }}{\text { Weight of sample }} \times 100 \%
$$

The procedure for testing the $\mathrm{SO}_{3}$ level in cement is as follows. A $1 \mathrm{~g}$ cement sample was put into a $100 \mathrm{ml}$ glass. A small amount of distilled water was added and stirred. $10 \mathrm{ml}$ of $\mathrm{HCl}$ was added. Distilled water was added to the glass so that the volume reached $100 \mathrm{ml}$ and heated to boiling. This solution was filtered using Whatman filter paper no. 41 . Then, $200 \mathrm{ml}$ of filtrate was taken. Next, $10 \mathrm{ml}$ of $10 \% \mathrm{BaCl}_{2}$ was added to the filtrate until a white precipitate was formed and it was undisturbed for 24 hours. The solution was filtered using Whatman filter paper no. 42. The filter paper and the precipitated product were put into a porcelain cup and dried in an oven at $110^{\circ} \mathrm{C}$ for 1 hour. Subsequently the porcelain dish and sediment chips were burned in a furnace at a temperature of $1000 \pm 50{ }^{\circ} \mathrm{C}$ for 45 minutes. The cup and sediment were weighed. The $\mathrm{SO}_{3}$ levels are calculated by the following equation.

$$
\mathrm{SO}_{3}(\%)=\mathrm{W} \times 34.3
$$

where $\mathrm{w}$ is the weight of $\mathrm{BaSO}_{4}(\mathrm{~g})$ and 34.3 is the ratio of $\mathrm{SO}_{3}$ molecules to $\mathrm{BaSO}_{4}(0.343)$ multiplied by 100 .

The sodium oxide $\left(\mathrm{Na}_{2} \mathrm{O}\right)$ and potassium oxide $\left(\mathrm{K}_{2} \mathrm{O}\right)$ contents can be determined by using the flame photometry method or the atomic absorption spectrophotometry method. The contents of other compounds in cement were tested by XRD. The process is like testing the chemical content in rice husk, but the material tested is cement.

\section{Results and discussion}

\subsection{Rice husk}

The use of rice husk as a substitute for coal fuel in the cement production process is presented in Figure 1. It is found that rice husk used as substitute fuel with average usage of 6.65 tonnes per hour. The use of rice husk as substitutive fuel is around $10.72 \%$ compared to the total 
fuel used in the clinker combustion. The use of rice husk can save about 3.4 tonnes of coal per hour.

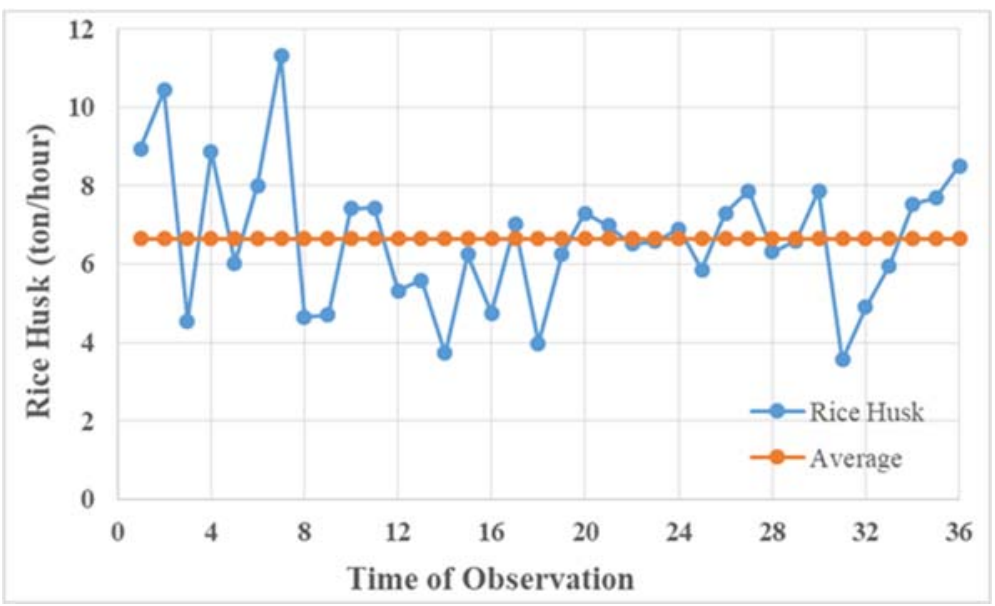

Fig. 1. Rice husk usage as substitute for coal fuel.

The calorific content of rice husk is shown in Figure 2. The figure describes the sampling time and the calorific value of rice husk. The average calorific value of rice husk is 2790 calories per gram. When compared to the calorific value of coal, the calorific value of rice husk is half that of coal. The low calorific value of rice husk is affected by the high water content. The water content values of the rice husk and the weight of the contents are shown in Figures 3 and 4.

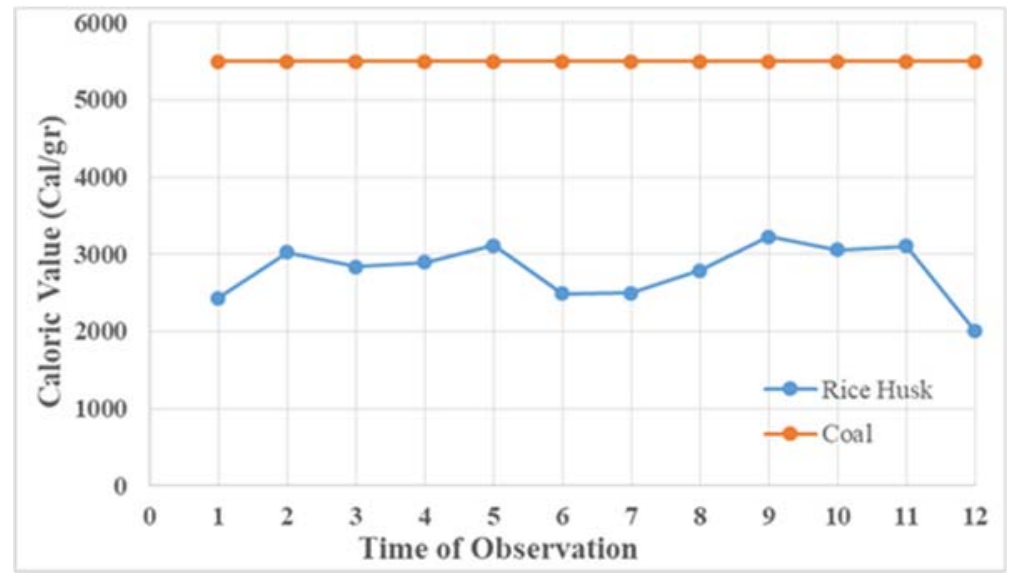

Fig. 2. Caloric value of rice husk. 


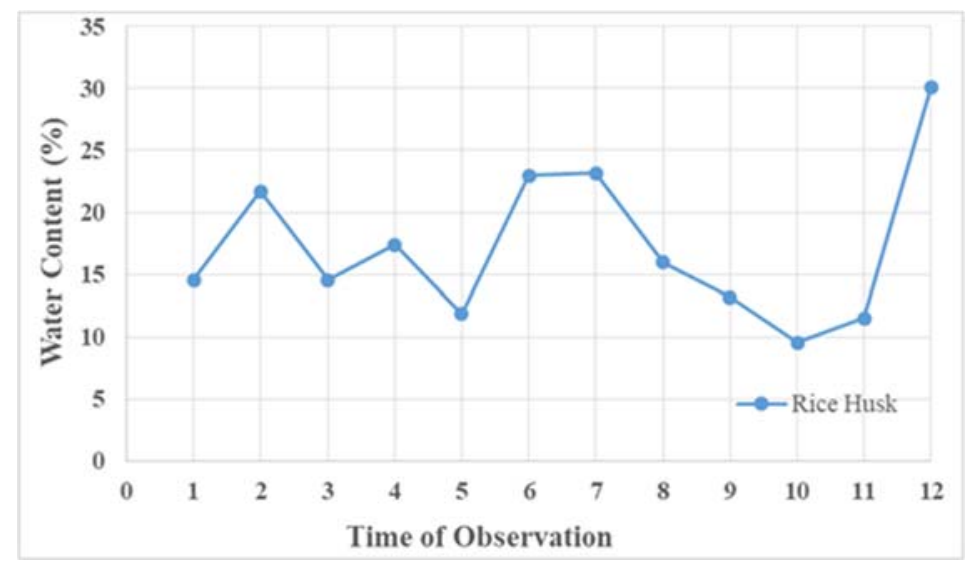

Fig. 3. Water content of rice husk.

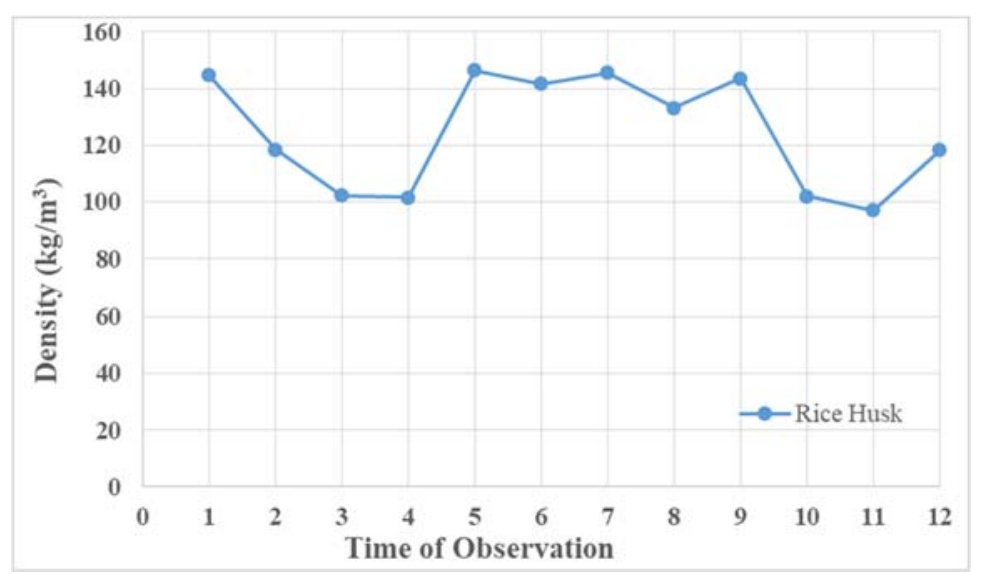

Fig. 4. Density of rice husk.

The water content of rice husk is very large. The maximum value of water content reaches $30 \%$. This will decrease the calorific value generated by burning rice husk. The average water content of rice husk is $17.20 \%$. This is due to open storage of rice husk. Because the stored rice husk is not protected by a roof, when it rains, all of the rain water will be absorbed by the rice husk. This causes a dramatic increase in the water content. The average density of rice husk is $124 \mathrm{~kg} / \mathrm{m}^{3}$. The low density, in addition to its physical nature consisting of small grains, makes it easy to pump rice husk into the inlet burner of a rotary kiln.

The chemical content of rice husk ash mostly consists of $\mathrm{SiO}_{2}$. This potential is utilized in the cement production process. The contents of $\mathrm{SiO}_{2}, \mathrm{Al}_{2} \mathrm{O}_{3}, \mathrm{Fe}_{2} \mathrm{O}_{3}, \mathrm{CaO}, \mathrm{MgO}, \mathrm{Na}_{2} \mathrm{O}$, and $\mathrm{K}_{2} \mathrm{O}$ are $92.03,1.39,0.67,1.23,0.82,0.33$, and $1.46 \%$ respectively.

\subsection{Cement}

The results for loss on ignition (LoI) and insoluble residue (IR) of cement are shown in Figures 5 and 6 . The average test result for loss on ignition of cement after the use of rice husk as substitute fuel is $4.98 \%$. This result is slightly lower than that given by the SNI 120492015 standard, which is 5\%. Meanwhile, the result of the insoluble residue test shows an average value of $2.40 \%$. This value of insoluble residue is better than the minimum required by the SNI, which is $3 \%$. The contents of compounds present in cement are shown in Table 2 . 


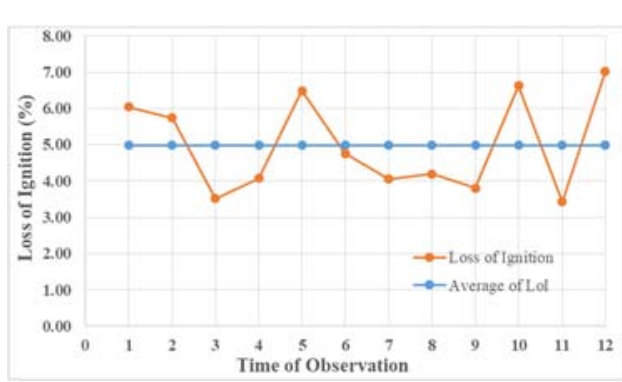

Fig. 5. Loss on ignition.

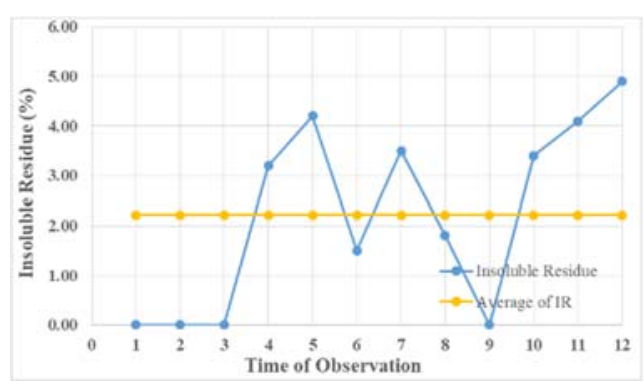

Fig. 6. Insoluble residue.

When the $\mathrm{MgO}$ content in the cement is excessive, it will form free $\mathrm{MgO}$ or periclase. Periclase in the cement will react with water to produce $\mathrm{Mg}(\mathrm{OH})_{2}$, which has a larger volume. This reaction also runs very slowly. When the concrete-hardening process is complete, the $\mathrm{MgO}$ and water reaction is still running. As a consequence, the excessive $\mathrm{MgO}$ content causes cracks in the concrete. According to Table 1, the MgO content of cement based on SNI-20492015 is $6 \%$, while the $\mathrm{MgO}$ content of the cement sample is $1.5 \%$ according to the test result. This means that the $\mathrm{MgO}$ content of the cement meets the requirements of SNI.

Table 2. Test results of chemical contents of cement.

\begin{tabular}{|c|c|c|c|c|c|c|c|c|c|c|c|c|c|c|}
\hline \multirow{2}{*}{ No } & \multirow{2}{*}{ Compound } & \multirow{2}{*}{ SNI } & \multicolumn{12}{|c|}{ Time of Observation } \\
\hline & & & 1 & 2 & 3 & 4 & 5 & 6 & 7 & 8 & 9 & 10 & 11 & 12 \\
\hline 1 & $\mathrm{SiO}_{2}$, min. & - & 18 & 18 & 18 & 18 & 19 & 20 & 18 & 18 & 19 & 18 & 18 & 17 \\
\hline 2 & $\mathrm{Al}_{2} \mathrm{O}_{3}, \max$ & - & 5.0 & 5.0 & 5.0 & 5.0 & 5.0 & 5.0 & 5.0 & 5.0 & 5.0 & 5.0 & 5.0 & 5.0 \\
\hline 3 & $\mathrm{Fe}_{2} \mathrm{O}_{3}, \max$ & - & 3.0 & 2.9 & 2.9 & 3.0 & 3.0 & 2.9 & 2.9 & 3.0 & 3.3 & 2.9 & 3.0 & 3.3 \\
\hline 4 & $\mathrm{MgO}, \max$ & 6 & 1.5 & 1.4 & 1.4 & 1.6 & 1.4 & 1.4 & 1.5 & 1.6 & 1.6 & 1.6 & 1.5 & 1.5 \\
\hline 5 & $\begin{array}{l}\mathrm{SO}_{3}, \max . \\
\text { If } \mathrm{C}_{3} \mathrm{~A} \leq 8 \\
\text { If } \mathrm{C}_{3} \mathrm{~A}>8\end{array}$ & $\begin{array}{l}3.0 \\
3.5\end{array}$ & 2.2 & 2.1 & 2.1 & 2.1 & 2.2 & 2.3 & 2.2 & 1.6 & 1.8 & 2.3 & 2.0 & 2.1 \\
\hline 6 & Alkali eq. & 0.6 & 0.3 & 0.3 & 0.3 & 0.4 & 0.4 & 0.5 & 0.3 & 0.3 & 0.3 & 0.5 & 0.4 & 0.5 \\
\hline 7 & IR, max. & 3.0 & 0.0 & 0.0 & 0 & 3.2 & 4.2 & 1.5 & 3.5 & 1.8 & 0.0 & 3.4 & 4.1 & 4.9 \\
\hline 8 & $\mathrm{C}_{3} \mathrm{~S}, \max$ & - & 58 & 68 & 70 & 58 & 46 & 43 & 67 & 66 & 60 & 59 & 57 & 58 \\
\hline 9 & $\mathrm{C}_{2} \mathrm{~S}$, min. & - & 9.0 & 8.0 & 0.9 & 8.6 & 21 & 24 & 0.8 & 2.0 & 8.9 & 6.5 & 8.2 & 5.9 \\
\hline 10 & $\mathrm{C}_{3} \mathrm{~A}, \mathrm{~min}$ & - & 8.0 & 8.5 & 8.1 & 8.9 & 8.5 & 9.0 & 8.0 & 8.1 & 7.8 & 8.5 & 8.5 & 8.7 \\
\hline 11 & $\begin{array}{l}\mathrm{C}_{4} \mathrm{AF} \quad+ \\
2 \mathrm{C}_{3} \mathrm{~A}, \max .\end{array}$ & - & 9.7 & 8.7 & 8.7 & 9.1 & 9.1 & 8.7 & 9 & 9.2 & 10 & 8.8 & 9.3 & 10.2 \\
\hline
\end{tabular}

The function of $\mathrm{SO}_{3}$ in cement is to improve its setting time. If the content is too high, it increases the volume and decreases the compressive strength of the concrete. SNI-2049-2015 requires an $\mathrm{SO}_{3}$ content of $3 \%$ if $\mathrm{C}_{3} \mathrm{~A} \leq 8 \%$ and $3.5 \%$ if $\mathrm{C}_{3} \mathrm{~A}>8 \%$. The $\mathrm{SO}_{3}$ content of the cement is $2.08 \%$ according to the test result. This means that the content of $\mathrm{SO}_{3}$ in the cement meets the requirements of SNI-2049-2015.

\section{Conclusions}

Based on the results and discussion above, some conclusions can be drawn as follows:

1. Rice husk can replace coal used in the cement industry as the ratio of the calorific value of rice husk to the calorific value of coal is 1 to 2 .

2. The use of rice husk as a fuel in the cement-making process has a good effect on the chemical content of cement produced in the cement industry. 
The authors would like to express their respect for and gratitude to Ir. Ning Nastiti, who provided the opportunity to do this research at PT Holcim Indonesia, Cilacap Plant.

\section{References}

1. Naveen, S. Bansal, Y. Antil, Int. J. Emer. Tech. 5, 1 (2015)

2. M.S. Kulkarni, P.G. Mirgal, P.P. Bodhale, S.N Tande, J. Civ. Eng. Env. Tech. 1, 1 (2014)

3. R.S. Deotale, S.H. Sathawane, A.R. Narde, Int. J. Sci. Eng. Res. 3, 6 (2012)

4. S.H. Sathawane, V.S. Bairagade, K.S. Kene, Proc. Eng. 51 (2013)

5. G.A. Habeeb, H.B, Mahmud, Mat. Res. 13, 2 (2010)

6. P.C. Kumar, N.V.S. Venugopal, P.M. Rao, J. Env. Prot. 4 (2013)

7. N.K. Krishna, S. Sandeep, K.M. Mini, I.O.P. Conf. Material Science and Engineering 149 (2016)

8. W.H.Wang, Y.F. Meng, D.Z. Wang, Kem. Ind. 66, 3-4 (2017)

9. A.E. Abalaka, Cons. Sci. 14 (2013)

10. A.N. Givi, s.A. Rashid, F.N.A. Aziz, M.A.M. Salleh, J. Am. Sci. 6, 3 (2010)

11. L.M. Farag, H.K.A. Hamid, Int. J. Energy Eng. 5, 2 (2015)

12. SNI 2049:2015, BSN (2015) 